\title{
Dysfunction of Synaptic Inhibition in Epilepsy Associated with Focal Cortical Dysplasia
}

\author{
Maria Elisa Calcagnotto, ${ }^{1}$ Mercedes F. Paredes, ${ }^{1,2}$ Tarik Tihan, ${ }^{3}$ Nicholas M. Barbaro, ${ }^{1}$ and Scott C. Baraban ${ }^{1,2}$ \\ ${ }^{1}$ Epilepsy Research Laboratory, Department of Neurological Surgery, ${ }^{2}$ Graduate Program in Neuroscience, and ${ }^{3}$ Department of Pathology, University of \\ California, San Francisco, San Francisco, California 94143
}

\begin{abstract}
Focal cortical dysplasia (FCD) is a common and important cause of medically intractable epilepsy. In patients with temporal lobe epilepsy and in several animal models, compromised neuronal inhibition, mediated by GABA, contributes to seizure genesis. Although reduction in GABAergic interneuron density has been reported in FCD tissue samples, there is little available information on the resulting physiological changes in synaptic inhibition and the potential contribution of these changes to epileptogenesis in the dysplastic human brain. Using visualized whole-cell patch-clamp recordings from identified neurons in tissue slices obtained from patients with FCD, we demonstrate that $\mathrm{GABA}_{\mathrm{A}}$-receptor-mediated inhibition is substantially altered in regions of dysplasia. These alterations include a significant reduction in IPSC frequency and a potentially compensatory decrease in transporter-mediated GABA reuptake function; the latter is marked by a significant increase in the decay-time constant for evoked and spontaneous IPSCs and a lack of effect of the GABA transportinhibitor 1-[2([(diphenylmethylene)imino] oxy)ethyl]-1,2,5,6-tetrahydro-3-pyridinecarboxylic acid hydrochloride on IPSC kinetics. Immunohistochemical staining revealed a scattering of GABAergic interneurons across dysplastic cortex and striking reductions in GABA transporter expression. Together, these results suggest that profound alterations in GABA-mediated synaptic inhibition play an essential role in the process of epileptogenesis in patients with FCD.
\end{abstract}

Key words: dysplasia; epilepsy; human brain slices; inhibition; GABA; GAT

\section{Introduction}

GABA is the main inhibitory neurotransmitter in the CNS and acts on both postsynaptic $\mathrm{GABA}_{\mathrm{A}}$ and presynaptic $\mathrm{GABA}_{\mathrm{B}}$ receptors. $\mathrm{GABA}_{\mathrm{A}}$ receptors mediate the majority of $\mathrm{GABA}$-dependent fast synaptic inhibition in the mammalian brain. Moreover, GABAergic inhibition plays a critical role in controlling normal circuit function (McCormick, 1989), limiting the spread of epileptiform discharges (Miller and Ferrendelli, 1990; Telfeian and Connors, 1998), regulating the intrinsic burst-firing properties of neurons (Isokawa-Akesson et al., 1989), and modulating the activation of glutamatergic synapses (Otis and Trussell, 1996). Impairment in the GABAergic system can lead to neuronal hyperexcitability that contributes to epileptogenesis (De Deyn et al., 1990; Tasker and Dudek, 1991). Alteration in GABA function may result from normal GABA receptors participating in abnormal circuitry or from loss of a subpopulation of inhibitory GABAergic interneurons. Epilepsy-associated alterations in the function and molecular composition of postsynaptic GABA receptor subunits have also been reported (Brooks-Kayal et al., 1998; Loup et al., 2000). Experimental models of temporal lobe epilepsy (TLE) are perhaps one of the best characterized exam-

Received June 29, 2005; revised Aug. 19, 2005; accepted Sept. 3, 2005.

This work was supported by National Institutes of Health Grant R01 NS40272-01. We thank D. Lowenstein for his comments on a previous version of this manuscript.

Correspondence should be addressed to S. C. Baraban, Department of Neurological Surgery, University of California, San Francisco, Box 0520, 533 Parnassus Avenue, San Francisco, CA 94143. E-mail: baraban@itsa.ucsf.edu. DOI:10.1523/JNEUROSCI.2687-05.2005

Copyright $\odot 2005$ Society for Neuroscience $\quad$ 0270-6474/05/259649-09\$15.00/0 ples in which loss of GABAergic interneurons is associated with reduced IPSC frequency (Kobayashi and Buckmaster, 2003; Austin and Buckmaster, 2004) and altered inhibitory circuit function (Zappone and Sloviter, 2004). Evidence from human studies further suggest that alteration in GABA-mediated inhibition contributes to the pathophysiology of TLE (Buhl et al., 1996; Gibbs et al., 1996; Arellano et al., 2004), but little is known about the function of GABA-mediated inhibition in human focal cortical dysplasia (FCD) (D’Antuono et al., 2004).

Malformations of cortical development are increasingly recognized as an underlying pathology in children with medically intractable epilepsy (Mischel et al., 1995; Porter et al., 2003). Seizures associated with these malformations are often resistant to available antiepileptic drugs and an understanding of how dysplastic neurons communicate is far from complete. The little we do know about synaptic function in a malformed brain is derived primarily from animal model research. For example, rodent models of cortical dysplasia exhibit a reduction in IPSC frequency (Zhu and Roper, 2000; Calcagnotto et al., 2002; Chen and Roper, 2003) and reduced numbers of parvalbumin-positive interneurons (Rosen et al., 1998; Roper et al., 1999). Inhibitory dysfunction in a malformed brain might result from altered arrangement of GABAergic inputs, loss of interneurons, or abnormal neurotransmitter reuptake in regions of dysplasia. If any of these alterations occur in humans with FCD, postsynaptic GABA-mediated synaptic function would appear to be substantially altered in dysplastic tissue. Such changes (if in the direction of reduced inhibition) might contribute to epileptogenesis. Inter- 
estingly, long-term reductions in interneuron density were noted in tissue samples from patients with FCD (Spreafico et al., 1998a,b, 2000; Garbelli et al., 1999; Alonso-Nanclares et al., 2005) but have not been correlated with epileptogenic changes in synaptic inhibition, although anatomical findings suggest a physiological condition of disrupted cortical function. To address whether GABA-mediated function is altered in a dysplastic brain, we examined IPSCs, interneuron distribution, and GABA-transporter (GAT) expression in neocortical tissue obtained during surgery from patients with medically intractable epilepsy and FCD. For comparison, we measured the same parameters in neocortical tissue obtained from patients undergoing surgery for medically refractory epilepsy who did not exhibit FCD.

\section{Materials and Methods}

Patients and tissue collection. Neocortical samples were obtained from patients who underwent surgery in the Department of Neurological Surgery at the University of California, San Francisco (UCSF) for medically intractable seizures associated with type II FCD (Palmini et al., 2004) ( $n=7$; patients aged 17-39 years; mean, 30 years) or mesial temporal lobe sclerosis (MTLS) (control patients; $n=9$; patients aged $18-39$ years; mean, 29 years). Tissue from an area with normal histology (i.e., nondysplastic) was taken from one patient with FCD as an additional control. All of the tissue specimens were from brain tissue that was removed as routine treatment for the patients' condition. The UCSF Committee on Human Research approved the protocol. Patients were taking a variety of antiepileptic drugs that were discontinued or reduced during the days preceding surgery (no clear bias toward a specific drug regimen was observed in either patient group) (Table 1). In FCD patients, tissue samples were obtained from regions identified as dysplastic on magnetic resonance imaging and confirmed post hoc by neuropathology. Within the suspected region of FCD, the most epileptogenic area was identified by using electrocorticographic (ECoG) recording (Fig. 1). In MTLS cases, nonspiking, nondysplastic neocortical tissue was used for comparison. Thus, although these patients had an epilepsy phenotype, the tissue chosen was as far away from the seizure focus (typically the hippocampus) as possible within the area to be resected. Neuropathological analysis of resected brain tissue revealed, in MTLS patients, a mild-tomoderate degree of gliosis, whereas cortical lamination was always preserved. In contrast, structural disruption along with the presence of large, aberrant neurons was seen in all tissue samples obtained from FCD patients. Table 1 summarizes the clinical and pharmacological data for all patients.

Slice preparation. Brain tissue was removed and placed in ice-cold oxygenated slicing medium, an artificial CSF (sACSF) consisting of the following (in mM): 220 sucrose, $3 \mathrm{KCl}, 1.25 \mathrm{NaH}_{2} \mathrm{PO}_{4}, 2 \mathrm{MgSO}_{4}, 26$ $\mathrm{NaHCO}_{3}, 2 \mathrm{CaCl}_{2}$, and 10 dextrose (295-305 mOsm). A sample containing cortical tissue was then rapidly transported to the laboratory and cut on a vibroslicer within $10-20 \mathrm{~min}$ of resection. Slices $300 \mu \mathrm{m}$ thick were cut in $4^{\circ} \mathrm{C}$ oxygenated $\left(95 \% \mathrm{O}_{2}, 5 \% \mathrm{CO}_{2}\right)$ sACSF and transferred immediately to a holding chamber where they remained submerged in oxygenated recording medium (nACSF) consisting of the following (in mM): $124 \mathrm{NaCl}, 3 \mathrm{KCl}, 1.25 \mathrm{NaH}_{2} \mathrm{PO}_{4}, 2 \mathrm{MgO}_{4}, 26 \mathrm{NaHCO}_{3}, 2 \mathrm{CaCl}_{2}$, and 10 dextrose (295-305 $\mathrm{mOsm})$. Slices were held at $37^{\circ} \mathrm{C}$ for $45 \mathrm{~min}$ and then allowed to come to room temperature. For each experiment, an individual slice was gently transferred to a submersion-type recording chamber where it was continuously perfused with oxygenated nACSF at room temperature.

Electrophysiology. Whole-cell voltage-clamp recordings were obtained from visually identified neurons using an infrared differential interference contrast (IR-DIC) video microscopy system (Stuart et al., 1993) (Fig. 2B). Patch electrodes (3-7 M $\Omega$ ) were pulled from 1.5-mm-outerdiameter borosilicate glass capillary tubing (World Precision Instruments, Sarasota, FL) using a micropipette puller (Sutter P-87; Sutter Instrument, Novato, CA), coated with Sylgard (Dow Chemical, Midland, $\mathrm{MI}$ ), and fire polished. Intracellular patch-pipette solution for whole-cell recordings contained the following (in $\mathrm{mM}$ ): 120 Cs-gluconate, 10 HEPES, 11 EGTA, $11 \mathrm{CsCl}_{2}, 1 \mathrm{MgCl}_{2}, 1.25 \mathrm{~N}$-ethyl bromide quaternary salt, $2 \mathrm{Na}_{2}$-ATP, and $0.5 \mathrm{Na}_{2}$-GTP, pH 7.25 (285-290 mOsm). Cells were filled with biocytin and analyzed post hoc (Fig. 2 B). To isolate GABAergic IPSCs, slices were perfused with nACSF containing $20 \mu \mathrm{M}$ 6,7dinitroquinoxaline-2,3-dione (DNQX) and $50 \mu \mathrm{M} \mathrm{D}-(-)$-2-amino-5phosphonovaleric acid (D-APV). Miniature IPSCs (mIPSCs) were recorded in ACSF supplemented with $1 \mu \mathrm{M}$ tetrodotoxin (TTX). IPSCs were recorded as outward currents at a holding potential of $0 \mathrm{mV}$, which is near the reversal potential for glutamatergic postsynaptic currents (Otis and Mody, 1992; Kobayashi et al., 2003). In some cells, spontaneous IPSCs (sIPSCs) and evoked IPSCs (eIPSCs) were recorded at different holding potentials $(-75$ and $-30 \mathrm{mV})$, because the decay kinetics can vary as a function of membrane potential (Otis and Mody, 1992). IPSCs were recorded from pyramidal cortical cells from FCD specimens ( $n=25$ cells) (Fig. $2 B$ ) or from pyramidal cells from normal cortical areas from MTLS specimens ( $n=25$ cells) and from a nondysplastic area in one patient with FCD (additional control).

eIPSCs were elicited at $0.1 \mathrm{~Hz}$ using a monopolar electrode placed in the white matter. Low-frequency $(0.1 \mathrm{~Hz}), 100 \mu$ s pulses were applied, and their intensity was increased until the threshold for eliciting a detectable monosynaptic eIPSC was reached. Stimulus intensity was then increased to two times the threshold and maintained at this intensity for the entire experiment. Because the recording and stimulating electrodes were separated by relatively large distances (e.g., recording electrode in layers II/III and stimulating electrode in the white matter), the decaytime constant of evoked IPSCs could be attributed, at least in part, to the release of GABA at multiple synapses situated on distal dendrites. The peak of the evoked response was examined (at a fast time resolution) to ensure that the measured response, a delay $>5 \mathrm{~ms}$, did not arise from shock artifact. Evoked and spontaneous IPSCs were abolished by bath application of $10 \mu \mathrm{M}$ bicuculline ( $n=10$ cells) to confirm a role for postsynaptic $\mathrm{GABA}_{\mathrm{A}}$ receptors. Voltage and current were recorded with an Axopatch 1D amplifier (Molecular Devices, Union City, CA) and monitored on an oscilloscope. Whole-cell voltage-clamp data were lowpass filtered at $1 \mathrm{kHz}$ ( $-3 \mathrm{~dB}$; eight-pole Bessel), digitally sampled at 10 $\mathrm{kHz}$, and monitored with pClamp software (Molecular Devices) running on a Pentium computer (Dell Computer, Round Rock, TX). The wholecell capacitance was similar for cells sampled in control and FCD tissue 

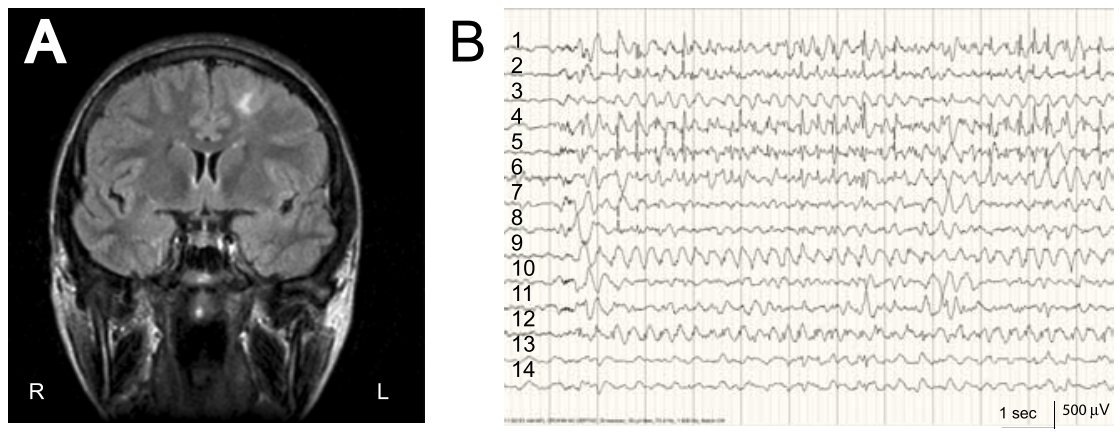

Cortical Dysplasia

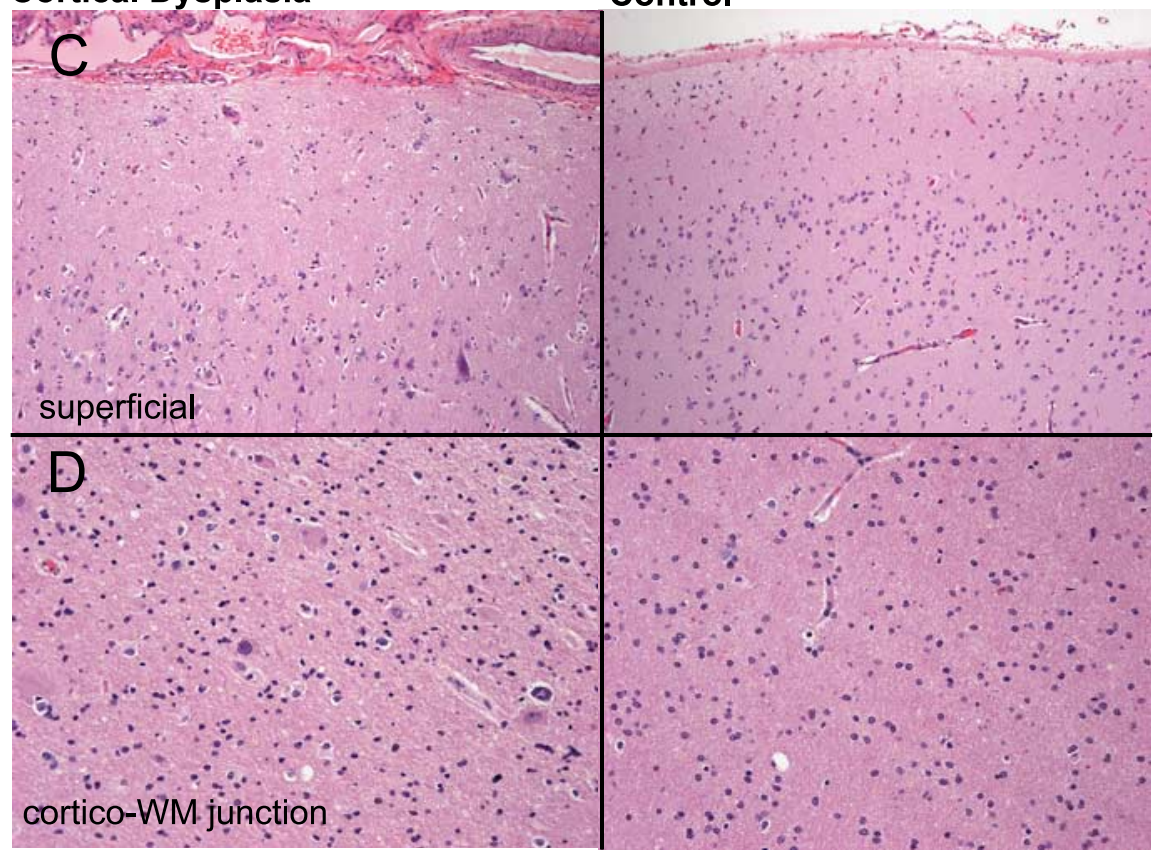

Figure 1. Representative magnetic resonance imaging (MRI), ECOG, and histology from a patient with FCD. $A$, Coronal MR section shows an area of FCD in the left frontal lobe. R, Right; $L$, left. $B, E C O G$ showing almost continuous paroxysmal activity recorded from the surface of the FCD. Bipolar montage in rows of 4: rows 1-3 represent the superior frontal lobe with anterior (1) and posterior (3) localization. Rows 4-6,7-9, and 10-12 represent subsequent inferior locations. Rows 13 and 14 represent referential recordings from monopolar electrodes placed in the bone edges with anterior (13) and posterior (14) localization. This ECOG shows epileptogenic activity mainly in rows $1,2,4$, and 5 , indicating a superior anterior focus. This corresponds precisely to the area of abnormality observed on the MRI. C, Hematoxylin and eosin (H\&E) staining of tissue from FCD (left) and control (right) patients showing all neocortical layers; the dysplastic tissue has lost the layered architecture that is seen in normal tissue and also has many bizarre cells present throughout (magnification, $100 \times$ ). D, H\&E stain of tissue at the cortico-white matter (WM) junction from a patient with FCD (left) and a control patient (right); note the excess number of cells in the FCD specimen (magnification, 200X).

$(30-43 \mathrm{pF})$, and the whole-cell access resistance was monitored carefully throughout the recordings. Cells were rejected if values changed by $>25 \%$ (or exceeded $20 \mathrm{M} \Omega$ ); only recordings with stable series resistance of $<20 \mathrm{M} \Omega$ were used for IPSC analysis.

Immunohistochemistry. Surgically removed tissue from both control and FCD patients were embedded in paraffin. The paraffin blocks (seven for controls and 30 for FCD) were cut into 5 - $\mu$ m-thick sections, and these samples were used for immunostaining for interneuronal markers. The sections were deparaffinized in xylene and rehydrated in five washes with decreasing concentrations of ethanol (100-70\%). Antigen retrieval was performed subsequently to enhance the final signal. Slides were immersed in antigen retrieval solution (DakoCytomation, Carpinteria, CA), pH 6, in a steamer for $20 \mathrm{~min}$. After several rinses with PBS, the slides were treated with $3 \% \mathrm{H}_{2} \mathrm{O}_{2}$ and, after blocking in lamb serum, were incubated with the primary antibody overnight at $4^{\circ} \mathrm{C}$. Antibodies used were anti-calbindin (mouse; Sigma, St. Louis, MO), antiparvalbumin (mouse; Sigma), and anti-glutamate decarboxylase
(GAD) 65/67 (rabbit; used to label the terminals and cell bodies of GABAergic interneurons; Sigma). Antibodies were visualized by using the ABC biotin-diaminobenzidine detection system (Vector Laboratories, Burlingame, CA).

Staining for GABA transporters was done on fresh, frozen surgical tissue. One-half of each of the surgical specimens was used for the electrophysiology experiments, and the other half was fixed overnight in $4 \%$ paraformaldehyde, cryoprotected in 30\% sucrose, and frozen. The frozen blocks were cut into $10-\mu \mathrm{m}$-thick sections. Immunostaining, without antigen retrieval, was performed as described above using antibodies against GAT-1 and GAT-3, the two transporters found in normotopically organized cortex (Conti et al., 2004) (rabbit; Novus Biologicals, Littleton, CO). For all immunhistochemical experiments, tissue samples from control and FCD were processed simultaneously. We included rodent tissue for each antibody used to confirm that the staining protocol was working during each immunostaining run. In addition, for the GABA transporter immunostaining experiments, we also stained equivalent tissue (from the same tissue block) with neuronal-specific nuclear protein, a neuron-specific antibody, to ensure sample quality.

We could not systematically quantify changes in the cells labeled by the interneuronal markers used, because we did not have equivalent pieces of tissue for all patients and serial sections through the focal cortical dysplasia were not available. However, we followed a qualitative protocol for analysis to identify any differences between control tissue and tissue from patients with FCD. Three separate investigators viewed each slide specimen and examined the following parameters for each slide: (1) intensity of staining, (2) the density of cells stained (high vs low), and (3) localization of labeled cells. The figures presented are representative of these evaluations.

Data analysis. Spontaneous IPSCs were measured using Mini Analysis 5.2.5 software (Synaptosoft, Decatur, GA). Each event was selected manually based on rise time, amplitude, and decay properties. Between 100 and 200 individual events were analyzed for each cell. Analysis was performed twice, first by an investigator blind to the status of the experiment and then by the experimenter. The frequency, interevent interval, amplitude, $10-$ $90 \%$ rise time, and area were measured. Evoked IPSCs were analyzed using Clampfit (Molecular Devices). Kinetic analysis of the IPSCs was performed with a single-exponential function. Results are presented as mean \pm SEM. Data before and after drug application were analyzed using a Student's $t$ test on the SigmaStat program (Jandel Scientific, San Rafael, CA). A one-way ANOVA was used to compare the results between different cell types. Significance level was set as $p<0.05$, unless otherwise noted.

\section{Results}

\section{Reduced IPSC in focal cortical dysplasia}

To examine the possibility that GABA-mediated synaptic inhibition is compromised in a cortical malformation, we recorded IPSCs in the presence of $50 \mu \mathrm{M}$ D-APV and $20 \mu \mathrm{M}$ DNQX. sIPSC 
frequency was significantly lower for pyramidal cells in dysplastic cortex $(1.9 \pm 0.2$ $\mathrm{Hz} ; n=25)$ than for pyramidal cells in control cortex taken from patients with MTLS $(3.1 \pm 0.3 \mathrm{~Hz} ; n=25$; ANOVA, $p<$ 0.001) (Fig. 2). Representative spontaneous and miniature IPSCs for each cell type are shown for direct comparison in Figure $2 \mathrm{~A}$. The shift toward higher interevent intervals in the cumulative histogram signifies that inhibition is reduced (Fig. 2D). The measured peak amplitudes and sIPSC $10-90 \%$ rise times showed no significant differences among cells from the two groups (amplitude: FCD, $27.3 \pm 3.5 \mathrm{pA}$; control, $28.3 \pm 2.8 \mathrm{pA}$; rise time: $\mathrm{FCD}$, $6.3 \pm 0.5 \mathrm{~ms}$; control, $5.4 \pm 0.4 \mathrm{~ms}$ ) and were suggestive of normal postsynaptic GABA-receptor function. To obtain an overall measure of inhibitory tone, we next performed a charge transfer calculation. By measuring the charge carried by individual sIPSC events as area under the current curve (Vreugdenhil et al., 2003; Di Paolo et al., 2004), a cumulative inhibitory current over a specified period of time could be calculated and compared between FCD and control tissue. For cells sampled in FCD tissue this value was $291 \pm 18 \mathrm{pA} \cdot \mathrm{ms}(\times 100)$, significantly smaller than that calculated for controls $[600 \pm 54 \mathrm{pA} \cdot \mathrm{ms}(\times 100) ; p<0.001]$.

To begin to distinguish whether reduced sIPSC frequency could be attributed to loss of inhibitory interneurons or to a reduced probability of presynaptic GABA release, we evaluated miniature IPSCs recorded in the presence of $1 \mu \mathrm{M}$ TTX, $50 \mu \mathrm{M}$ D-APV, and $20 \mu \mathrm{M}$ DNQX (Fig. 2 A). Consistent with spontaneous IPSC findings, mIPSCs recorded from pyramidal cells in dysplastic tissue had significantly lower frequencies ( $1.2 \pm 0.3 \mathrm{~Hz} ; n=7)$ compared with mIPSCs recorded on control cells $(2.5 \pm 0.5 \mathrm{~Hz} ; n=7$; ANOVA, $p<$ 0.05 ) (Figs. $2 A, C, D)$. Again, the mIPSC measured peak amplitudes and 10-90\% rise times from FCD and control cortex showed no significant differences (amplitude: FCD, $15.2 \pm 1.5 \mathrm{pA}$; control, $13.8 \pm 0.6 \mathrm{pA}$; rise time: FCD, $3.8 \pm 0.5 \mathrm{~ms}$; control, $4.9 \pm 0.3 \mathrm{~ms}$ ). These findings suggest that GABA-mediated synaptic inhibition is functionally reduced in patients with FCD.

\section{Alterations in interneuron distribution in focal cortical dysplasia}

To determine whether the decrease in IPSC frequency in FCD is associated with interneuronal abnormalities, we used immunohistochemistry to compare the density and distribution of interneurons between FCD and nondysplastic tissue specimens. We used an antibody against GAD to label the terminals and cell bodies of GABAergic interneurons (Hiscock et al., 2000). The ${ }^{* *} p<0.05$; ANOVA.

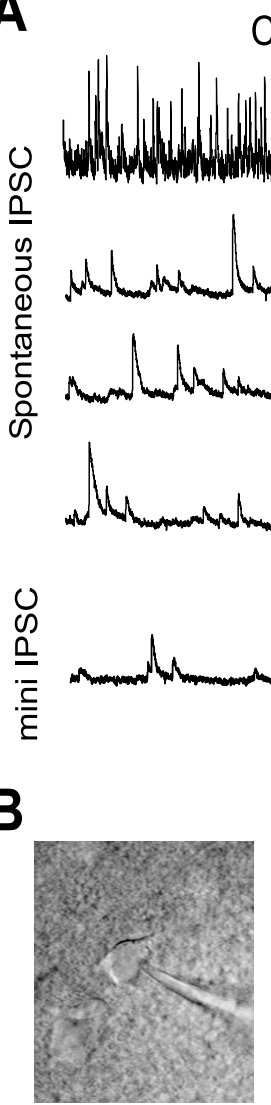

IR-DIC
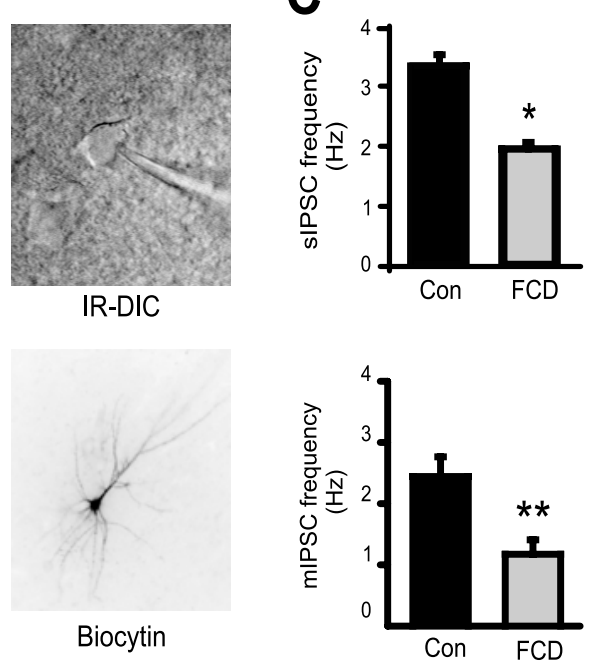

FCD
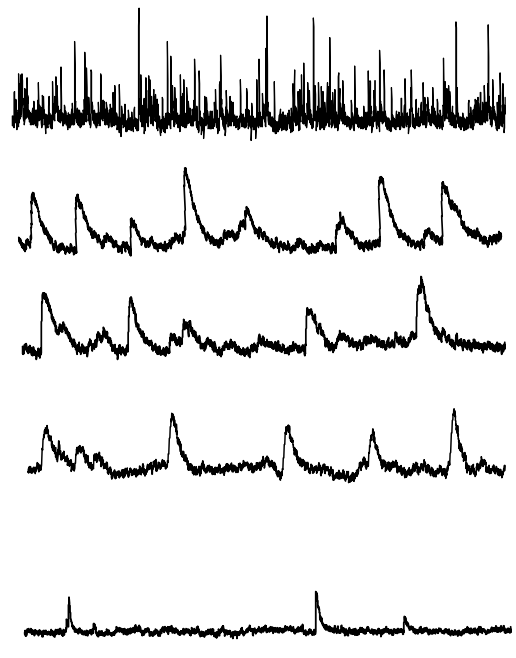

D
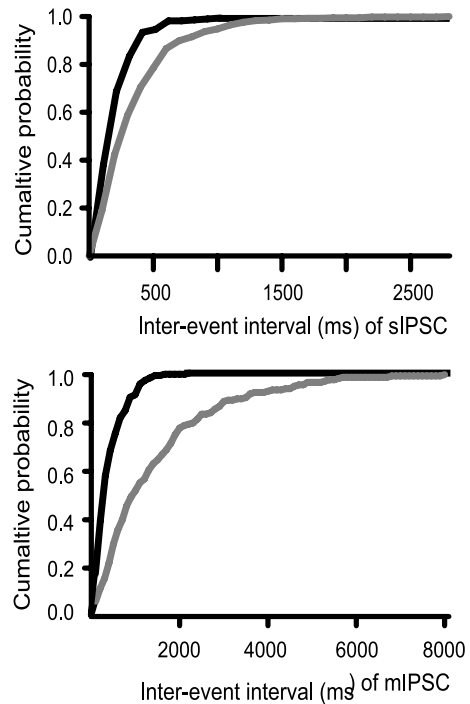

Figure 2. Whole-cell visualized patch-clamp recoding in cortical control and dysplastic cells. A, sIPSCs and mIPSCs (mini IPSC) of cortical pyramidal cells from control and FCD groups. B, IR-DIC imaging (top) and biocytin filling (bottom) of a pyramidal neuron in cortical tissue sample resected from patients with FCD.C, Plots of frequency of sIPSCs and mIPSCs of cortical pyramidal cells from control (Con) and FCD groups. Note the significantly lower sIPSCs and mIPSCs frequencies for dysplastic cells $\boldsymbol{D}$, Cumulative probability plots of interevent intervals of sIPSCs and mIPSCs on control (black) and FCD (gray) cells. Note that the curve of the interevent interval for $F C D$ is shifted to the right (lower frequency), compared with controls. Error bars indicate SEM. ${ }^{*} p<0.001$;

general GAD-expression pattern did not indicate a clear difference in overall distribution of interneurons between FCD and nondysplastic tissue specimens (Figs. $3 A, D$ ). However, when we looked at the expression of parvalbumin and calbindin, $\mathrm{Ca}^{2+}$ binding proteins that can also serve as markers for subpopulations of GABAergic interneurons (Van Brederode et al., 1990; del Rio and DeFelipe, 1996), we observed a striking difference in the regionalization of these cell types. In nondysplastic neocortical control tissue, calbindin- and parvalbumin-positive cells were confined primarily to neocortical layers II/III (Figs. $3 B, C$ ). In contrast, tissue from patients with FCD showed an abnormal distribution of these cells throughout all cortical layers; some areas contained small clusters of interneurons, whereas in many regions, calbindin- and parvalbumin-positive cells were scarce (Figs. $3 E, F$ ). 


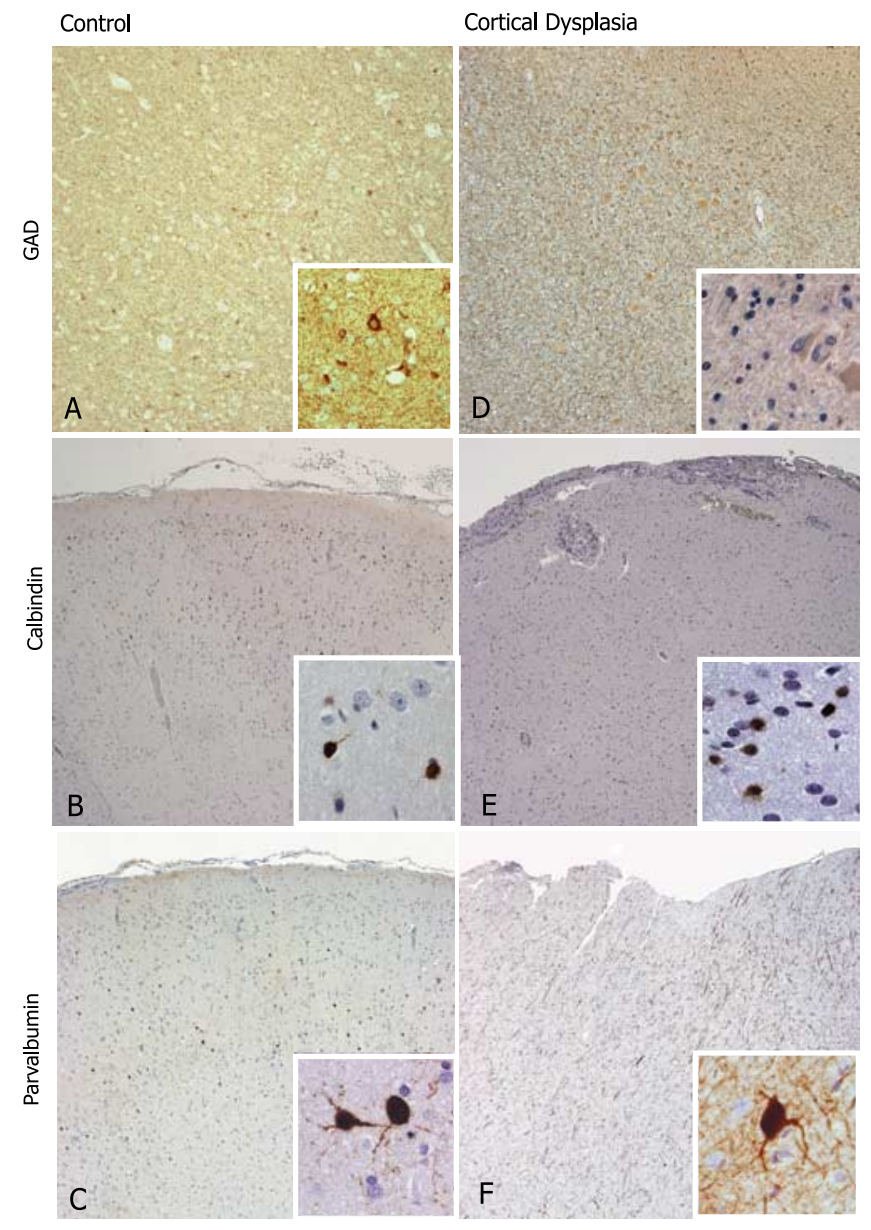

Figure 3. Immunostaining of dysplastic tissue with interneuronal markers reveals abnormal interneuronal distribution. Expression of $\operatorname{GAD}(\boldsymbol{A}, \boldsymbol{D})$, calbindin $(\boldsymbol{B}, \boldsymbol{E})$, and parvalbumin $(\boldsymbol{C}, \boldsymbol{F})$ shows no significant change in the overall numbers of interneurons in dysplastic tissue (compare $A, D$ ) but does show loss of regionalization of a subpopulation of interneurons (compare $\boldsymbol{B}, \boldsymbol{C}$ and $\boldsymbol{E}, \boldsymbol{F}$ ). The insets at higher magnification do not reveal any severe changes in morphology (original magnification, $40 \times$ ).

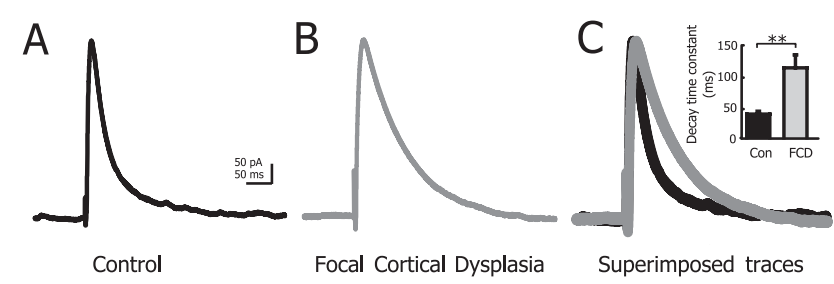

Figure 5. Changes in decay-time constant of eIPSCs from cortical control cells compared with those from dysplastic cells. Representative eIPSC recordings obtained from control pyramidal cells (black; $\boldsymbol{A}$ ) and dysplastic cells (gray; $\boldsymbol{B}$ ) and superimposed traces of eIPSCs of cells from control (Con; black) and FCD (gray; $\boldsymbol{C}$ ) tissue. Note the significantly prolonged elPSCs decay for dysplastic cells (compared with control cells; inset graph). Error bars indicate SEM. ${ }^{* *} p<$ 0.001; ANOVA.

\section{Dysfunctional GABA transport in FCD}

Our recent analysis of hippocampal heterotopia in an animal model of malformation reported a potentially "compensatory" increase in IPSC decay time and corresponding decrease in GABA reuptake (Calcagnotto et al., 2002). To examine whether a similar change occurs in FCD patients, additional analysis of IPSC kinetics was performed. The decay-time constant for sIPSCs in dysplastic neurons was $67 \%$ greater than that measured in control cells (FCD, $10.3 \pm 1.7 \mathrm{~ms}, n=18$; control, $6.5 \pm 0.3$ ms, $n=25$; ANOVA, $p<0.05$ ) (Figs. $4 A, B$ ); no significant differences in the decay-time constant were noted for mIPSCs (FCD, $5.7 \pm 1.0 \mathrm{~ms}, n=7$; control, $4.7 \pm 1.2 \mathrm{~ms}, n=7$ ) (Figs. $4 D, E)$. To describe more fully the difference in sIPSC decay times, event histograms were constructed for representative cells (Fig. 4C). A significant shift toward longer decay-time constant for dysplastic-neuron sIPSCs was noted in comparison with control cells (Fig. 4C); no shift was noted for mIPSCs (Fig. $4 F$ ). IPSCs recorded from cells at different holding potentials $(-75$ and -30 $\mathrm{mV} ; n=6$ ) also revealed a slower decay-time constant for dysplastic cells when compared with those measured in control cells (data not shown). Next, we examined the kinetics of evoked IPSCs. In the presence of DNQX and D-APV, white-matter stimulation consistently elicited a $\mathrm{GABA}_{\mathrm{A}}{ }^{-}$ receptor-mediated IPSC. Comparison of IPSCs evoked in control $(n=34)$ and dysplastic neurons $(n=22)$ also revealed a clear prolongation in current decay in dysplastic neurons $(\mathrm{FCD}, 112.5 \pm 19.5 \mathrm{~ms}$, $n=26$; control, $38.5 \pm 2.4 \mathrm{~ms}, n=34$; ANOVA, $p<0.001$ ) (Fig. 5). If the prolonged IPSCs result from altered GABA transport and reuptake, we would expect application of a GAT inhibitor to increase the duration of evoked (or spontaneous) GABA responses on normal cells but produce little (or no) effect on dysplastic neurons. To test this possibility, we examined the kinetic properties of IPSCs in the presence of 1-[2([(diphenylmethylene) imino] oxy)ethyl]-1,2,5,6-tetra-hydro-3pyridinecarboxylic acid hydrochloride (NO-711), a selective GAT-1 inhibitor (Borden et al., 1994). Bath application of NO-711 $(50 \mu \mathrm{M})$ had no effect on the decaytime constant for eIPSCs recorded from dysplastic neurons $(n=8)$ (Fig. $6 A, B)$. As expected, NO-711 produced a significant prolongation of the decay-time constant for

Figure 4. Changes in decay-time constant of sIPSCs and mIPSCs from cortical control pyramidal cells compared with those from dysplastic cells. Superimposed traces of SIPSCS $(\boldsymbol{A})$ and mIPSCS (Mini IPSC; $\boldsymbol{D}$ ) of cells from control (black) and FCD (gray) groups are shown. Graphs of decay-time constant of sIPSCs $(\boldsymbol{B})$ and $\operatorname{mIPSCs}(\boldsymbol{E})$ of cortical pyramidal cells from control and FCD groups are shown. Note the significantly prolonged sIPSCs decay for dysplastic cells (compared with control cells). Representative event histograms of sIPSCs ( () and mIPSCs $(\boldsymbol{F})$ decay-time constant from control (black) and FCD (gray) groups are shown. Decay-time constant are plotted for 100 individual events. Note that sIPSCs from dysplastic neurons have longer decay-time constant than control cells. Error bars indicate SEM. ${ }^{*} p<0.05$; ANOVA. Con Control. 


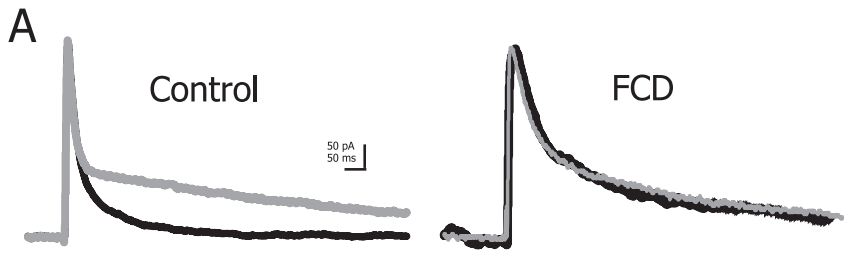

B
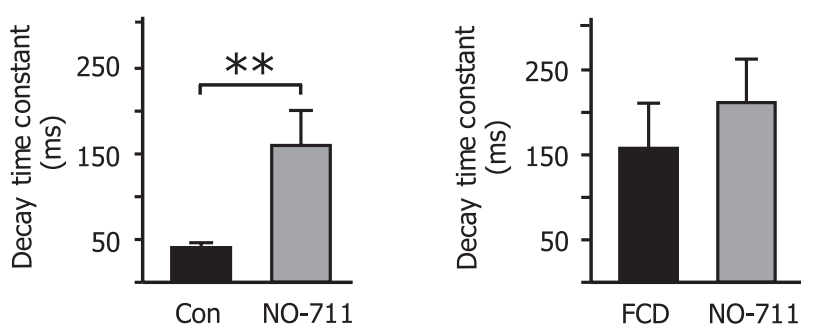

Figure 6. Dysplastic neurons show a GABA transporter defect. $\boldsymbol{A}$, Average traces of elPSC before (control and FCD; black) and after (gray) application of N0-711. B, Graphs of effect of N0-711 (gray) on the decay-time constant of eIPSC for control (Con) and dysplastic (black) cells N0-711 did not significantly alter the eIPSC decay-time constant on dysplastic cells but increased the eIPSC decay-time constant on control cells. Error bars indicate SEM. ${ }^{* *} p<0.001$; Student's $t$ test.

eIPSCs recorded from control cells $(n=12)$ (Fig. $6 A, B)$. Similarly, bath application of NO-711 $(50 \mu \mathrm{M})$ had no effect on the decay-time constant for spontaneous IPSCs recorded from dysplastic neurons ( $n=3$; two patients) but produced a $295 \%$ prolongation in decaytime for sIPSCs recorded from control cells ( $n=3$; two patients).

To further explore a role for GABA transporters in the decay changes observed, we immunohistochemically examined the expression of two transporters found in normotopically organized cortex (i.e., GAT-1 and GAT-3). For both transporters, we observed a dramatic decrease in immunoreactivity throughout the FCD tissue. Puncta in FCD specimens were not as large as in control tissue, and the dense distribution of GAT transporters that typically outline neurons was essentially absent (Fig. 7). The observed reductions in transporter function and/or expression could impair GABA reuptake in malformed cortex and prolong GABA-mediated synaptic events (i.e., increase the IPSC decaytime constant) in dysplastic neurons (Fig. 6).

\section{Discussion}

Although physiological alterations in GABA-mediated inhibition are well described in animal models of epilepsy (Kamphuis et al., 1989; Roper et al., 1999; Austin and Buckmaster, 2004), studies in human samples from epileptic patients have mainly addressed the molecular and anatomical changes associated with the GABAergic system. For example, one of the earliest examinations of tissue resected from TLE patients reported a reduction in somatostatin-immunoreactive hilar interneurons (de Lanerolle et al., 1989). Subsequent studies in human tissue obtained at surgery (Spreafico et al., 1998a; Williamson et al., 1999; Thom et al., 2004; Wittner et al., 2005) or rodent models (Roper et al., 1999; Austin and Buckmaster, 2004) consistently describe a loss of specific interneuron subpopulations. In TLE, the surviving GABAergic interneurons can make new inhibitory synapses with granule cells (Davenport et al., 1990; Mathern et al., 1995; Andre et al., 2001), provide a robust paired-pulse inhibition at the extracellular level (Buckmaster and Dudek, 1997), and are associated with alterations in postsynaptic $\mathrm{GABA}_{\mathrm{A}}$ receptor expression (Brooks-Kayal et al., 1998). Many of these findings have been replicated in rodent TLE models. An interesting and potentially controversial recent observation suggesting reduced IPSC frequency on dentate granule cells was made by Kobayashi and Buckmaster (2003) in a well characterized rodent TLE model. Whether tissue samples from patients with medically intractable FCD also exhibit altered levels of GABA-mediated inhibition was examined here for the first time. The main findings of our study on GABAergic inhibition in human FCD are (1) decreased IPSC frequency and decreased cumulative GABA-mediated synaptic currents in regions of FCD that could be related to changes in the density and/or distribution of interneurons within the malformed cortex and (2) increased duration of GABAergic events that are associated with a decrease in GABA-transporter expression in FCD.

Despite considerable research attention the exact mecha$\operatorname{nism}(\mathrm{s})$ by which seizures are generated in a dysplastic brain remain unknown. Not surprisingly, it has been suggested that aberrant expression of NMDA receptors play a role in seizure genesis. Immunohistochemical analysis of adult FCD tissue indicates that NR2A/B subunits coassemble with NR1 in dysplastic, but not nondysplastic, pyramidal neurons (Babb et al., 1998; Najm et al., 2000). Using single-cell amplification techniques, Crino et al. (2001) reported a decrease of NR2A and an increase of NR2B mRNA levels in dysplastic cells from fixed adult FCD samples. Both findings are consistent with a conclusion that glutamate-mediated excitation is enhanced. Electrophysiological findings from one sampling of pediatric FCD patients, however, indicate a decrease in NMDA-mediated current density for cytomegalic neurons, decreased $\mathrm{Mg}^{2+}$ and ifenprodil sensitivity, and reduced NR2B immunoreactivity (Andre et al., 2004). Whether synaptic excitation is increased (or decreased) in regions of dysplasia and whether altered glutamate receptor-mediated excitation plays a critical role in FCD-associated epilepsy cannot be determined from these disparate findings. Analysis of field potentials in tissue slices obtained from FCD patients has indicated a capability to generate GABA-mediated synchronous potentials after exposure to a convulsant agent (4-aminopyridine) (Avoli et al., 2003; D’Antuono et al., 2004). Unfortunately, the epileptogenic significance of these findings is unclear, given that similar potentials can be elicited in normal tissue slices exposed to this agent. Overall, these studies highlight the emphasis (thus far) on sophisticated functional analysis of glutamate-mediated excitation in a dysplastic brain, a level of analysis that has not yet been applied to GABAergic systems.

\section{Reduced GABAergic inhibition in focal cortical dysplasia}

Our observed reduction in the frequency of inhibitory events recorded on pyramidal cells within dysplastic tissue (with no clear difference in IPSC amplitude) is consistent with a presynaptic alteration of synaptic inhibition. Electrophysiological recordings such as these provide direct evidence for reduced GABA-mediated inhibition in FCD patients. Furthermore, this decreased inhibition, even in the absence of additional defects, could be sufficient for the generation of seizures, because even small reductions in GABA-mediated function were shown to induce abnormal electrical discharge (Powell et al., 2003; Cobos et al., 2005). Interestingly, a reduction in IPSC frequency was reported in a rodent model of cortical dysplasia (caused by prenatal irradiation) featuring hyperexcitability and rare spontaneous seizures (Zhu and Roper, 2000; Chen and Roper, 2003; Kellinghaus et al., 2004). In both human tissue and experimental models, this reduced IPSC frequency could result from a decreased release of GABA at presynaptic terminals or simply from an impairment of GABAergic terminals and/or cells within the FCD. A presynaptic 


\section{Control}
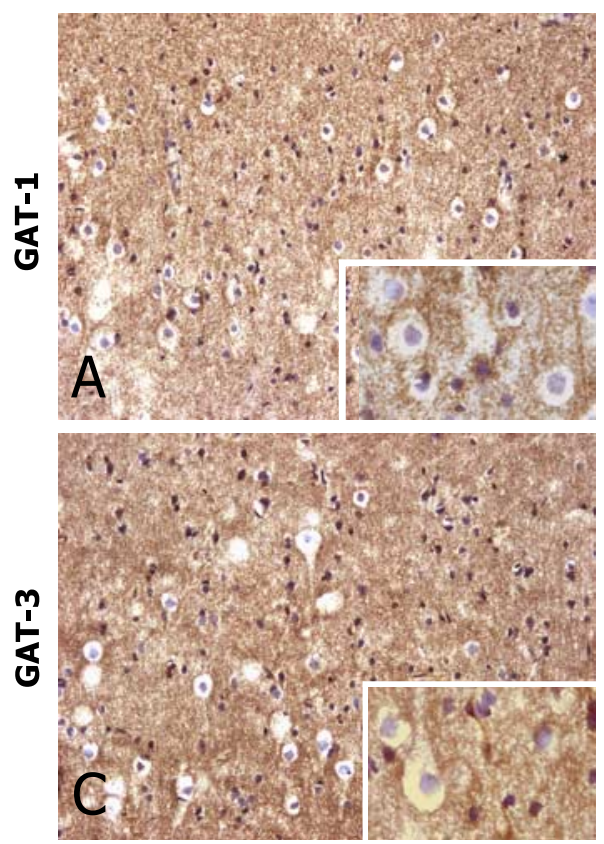

\section{Cortical Dysplasia}
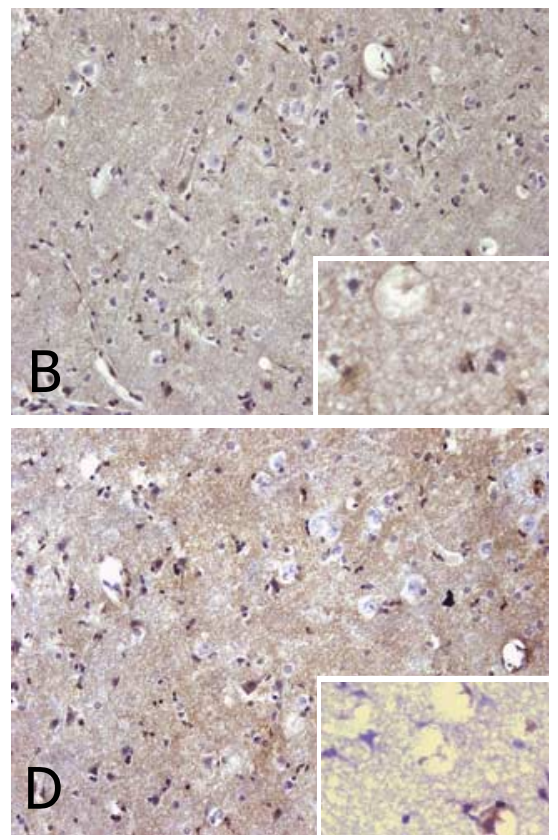

Figure 7. Dysplastic tissue from patients with FCD showed a decrease of cortical GABA transporters. Immunostaining for GAT-1 in control tissue $(\boldsymbol{A})$ and tissue from a patient with focal cortical dysplasia $(\boldsymbol{B})$ showed a loss of the transporter protein in the abnormal tissue. The expression of GAT-3 in control tissue (C) and FCD tissue $(\boldsymbol{D})$ was similar (magnification, $200 \times$; inset magnification, $400 \times$ ).

disturbance is suggested by our finding of abnormally distributed GABAergic interneurons in dysplastic cortex, including clusters separated by gaps containing few or no GABAergic cells. Moreover, the reduced synaptic inhibition observed on dysplastic pyramidal neurons (Fig. 2) does not require a frank loss of GABAergic interneurons but could result from a diffuse (or limited) distribution of inhibitory inputs corresponding to the scattering of interneurons across a wide region of dysplastic cortex or lack of synapses between clustered GABAergic terminals and the cell bodies of dysplastic cells (Garbelli et al., 1999).

Our findings are entirely consistent with previous anatomical studies reporting a "widespread decrease" in GAD-immunoreactive neurons in dysplastic tissue (Spreafico et al., 1998a,b, 2000). As additional examples of this potentially common interneuron defect, a reduction in immunoreactivity against parvalbumin and calcium-binding proteins was also noted in dysplastic cortex from irradiated rats (Roper et al., 1999), from patients with nodular neuronal heterotopia (Hannan et al., 1999), in the hippocampi of experimental models of TLE (Houser et al., 1986; Ribak et al., 1986), and from patients with TLE (Ferrer et al., 1992, 1994; DeFelipe et al., 1993; Marco et al., 1996). Because quantitative analysis or staining of serial sections throughout the entire dysplastic area has not been performed in human tissue studies, we cannot infer from histological data alone that these alterations are homogeneous in the dysplastic region. At best, these studies represent "snapshots" of how interneurons may be distributed in a dysplastic brain. A more conservative interpretation of these anatomical snapshots is that they suggest reduced numbers (or uneven distribution) of GABA-containing interneurons in regions of FCD and that this reduction could be directly associated with observed changes in synaptic physiology. From this work, we hypothesize that altered inhibitory circuitry is a contributing factor to the epileptic phenotype observed in FCD patients.

\section{Impairment of GABA transport in focal} cortical dysplasia

Another interesting finding in our study was the prolongation of GABA-evoked synaptic currents in pyramidal cells within the FCD. This increase in IPSC duration could be attributed to a presynaptic increase of GABA released by the interneuron terminals, postsynaptic changes in $\mathrm{GABA}_{\mathrm{A}}$ receptors, or changes in GABA transporters. However, the larger IPSC decay-time in FCD tissue is unlikely to be produced by the increased release of GABA, because the IPSC frequency is decreased and interneurons are abnormally distributed throughout the cortical regions. Although alterations in postsynaptic $\mathrm{GABA}_{\mathrm{A}}$ receptors cannot be ruled out at this time, our observations would indicate that the impairment of GABA transport reuptake with consequent increased neurotransmitter levels in the extracellular space around dysplastic neurons causes the prolonged IPSC decay-time constant in the dysplastic areas. That the decay-time constant for miniature IPSCs did not change could be attributed to the idea that GABA clearance for mIPSCs (and thus kinetics) are more closely related to diffusion than GABA reuptake. This could also explain why GABA uptake blockers, such as tiagabine, normally have no effect on mIPSC kinetics (Thompson and Gahwiler, 1992; Isaacson et al., 1993). The blockage of GABA transporters hinders the proper removal of GABA from the synaptic cleft, thereby prolonging the decay-time for spontaneous and evoked events (Isaacson et al., 1993; Soudijn and van Wijngaarden, 2000). As we demonstrated here, application of a GABA-transport inhibitor did not alter the eIPSC decay-time constant in cells from FCD tissue but did prolong the eIPSC decay time in pyramidal cells from control tissue, as would be expected for a normal cell. This finding is corroborated by our observation of a qualitative decrease in GAT-1 and GAT-3 expression within the dysplastic region. We suggest that a decrease in GAT function could be a compensatory mechanism to reduce the hyperexcitability associated with a dysplastic lesion. Indeed, compensatory impairment of GABA-transporter expression was reported in a previous study from this laboratory of a rodent model featuring nodular heterotopias in the hippocampal formation (Calcagnotto et al., 2002). Although not interpreted as compensatory at the time, similar GAT transporter defects were described in hippocampal tissue samples obtained from TLE patients (Patrylo et al., 2001) and patients with FCD (Spreafico et al., 2000). Clearly, it will be necessary to elucidate the developmental timing of IPSC and transporter defects to determine whether a loss of inhibition precedes changes in GAT transporter function.

\section{Conclusion}

Animal models have limitations in how well they replicate the human disease and how directly applicable they are for analysis of complex neurological disorders such as epilepsy. Despite these inherent limitations, it is interesting that some of the electrophysiological findings reported here have been described previously in rodent models of cortical malformation (Zhu and Roper, 2000; Calcagnotto et al., 2002; Chen and Roper, 2003). Human tissue 
samples, on the other hand, limit experimental design in that strict age-matched control samples from nonepileptic patients are rarely available for comparison. Nonetheless, obtaining a better understanding of how seizures can be generated in dysplastic human neocortex ultimately requires examination of available human tissue samples. By demonstrating a reduced inhibitory drive to dysplastic neurons, our data fit with a long-standing conclusion that reduced inhibition (i.e., inadequate control of excitation) results in epilepsy (De Deyn et al., 1990; Jefferys and Whittington, 1996; Macdonald and Kapur, 1999; Cossart et al., 2005). This work, like much of what we have learned from previous animal and human studies, strongly suggests a critical role for GABA-mediated inhibition in the overall control of neural excitability. Thus, our findings provide a new perspective on the epileptogenic process in dysplastic brain tissue and suggest potential therapeutic targets (e.g., alternative methods to augment inhibition via cell replacement) for the treatment of intractable epilepsy associated with focal cortical dysplasia.

\section{References}

Alonso-Nanclares L, Garbelli R, Sola RG, Pastor J, Tassi L, Spreafico R, DeFelipe J (2005) Microanatomy of the dysplastic neocortex from epileptic patients. Brain 128:158-173.

Andre V, Marescaux C, Nehlig A, Fritschy JM (2001) Alterations of hippocampal GABAergic system contribute to development of spontaneous recurrent seizures in the rat lithium-pilocarpine model of temporal lobe epilepsy. Hippocampus 11:452-468.

Andre VM, Flores-Hernandez J, Cepeda C, Starling AJ, Nguyen S, Lobo MK, Vinters HV, Levine MS, Mathern GW (2004) NMDA receptor alterations in neurons from pediatric cortical dysplasia tissue. Cereb Cortex 14:634-646.

Arellano JI, Munoz A, Ballesteros-Yanez I, Sola RG, DeFelipe J (2004) Histopathology and reorganization of chandelier cells in the human epileptic sclerotic hippocampus. Brain 127:45-64.

Austin JE, Buckmaster PS (2004) Recurrent excitation of granule cells with basal dendrites and low interneuron density and inhibitory postsynaptic current frequency in the dentate gyrus of macaque monkeys. J Comp Neurol 476:205-218.

Avoli M, Louvel J, Mattia D, Olivier A, Esposito V, Pumain R, D'Antuono M (2003) Epileptiform synchronization in the human dysplastic cortex. Epileptic Disord 5 [Suppl 2]:S45-S50.

Babb TL, Ying Z, Hadam J, Penrod C (1998) Glutamate receptor mechanisms in human epileptic dysplastic cortex. Epilepsy Res 32:24-33.

Borden LA, Murali Dhar TG, Smith KE, Weinshank RL, Branchek TA, Gluchowski C (1994) Tiagabine, SK\&F 89976-A, CI-966, and NNC-711 are selective for the cloned GABA transporter GAT-1. Eur J Pharmacol 269: 219-224.

Brooks-Kayal AR, Shumate MD, Jin H, Rikhter TY, Coulter DA (1998) Selective changes in single cell GABA(A) receptor subunit expression and function in temporal lobe epilepsy. Nat Med 4:1166-1172.

Buckmaster PS, Dudek FE (1997) Neuron loss, granule cell axon reorganization, and functional changes in the dentate gyrus of epileptic kainatetreated rats. J Comp Neurol 385:385-404.

Buhl EH, Otis TS, Mody I (1996) Zinc-induced collapse of augmented inhibition by GABA in a temporal lobe epilepsy model. Science 271:369-373.

Calcagnotto ME, Paredes MF, Baraban SC (2002) Heterotopic neurons with altered inhibitory synaptic function in an animal model of malformationassociated epilepsy. J Neurosci 22:7596-7605.

Chen HX, Roper SN (2003) Reduction of spontaneous inhibitory synaptic activity in experimental heterotopic gray matter. J Neurophysiol 89:150-158.

Cobos I, Calcagnotto ME, Vilaythong AJ, Thwin MT, Noebels JL, Baraban SC, Rubenstein JRL (2005) Mice lacking Dlx1 show subtype-specific loss of interneurons, reduced inhibition and epilepsy. Nat Neurosci 8:1059-1068.

Conti F, Minelli A, Melone M (2004) GABA transporters in the mammalian cerebral cortex: localization, development and pathological implications. Brain Res Brain Res Rev 45:196-212.

Cossart R, Bernard C, Ben-Ari Y (2005) Multiple facets of GABAergic neu- rons and synapses: multiple fates of GABA signalling in epilepsies. Trends Neurosci 28:108-115.

Crino PB, Duhaime AC, Baltuch G, White R (2001) Differential expression of glutamate and GABA-A receptor subunit mRNA in cortical dysplasia. Neurology 56:906-913.

D’Antuono M, Louvel J, Kohling R, Mattia D, Bernasconi A, Olivier A, Turak B, Devaux A, Pumain R, Avoli M (2004) GABAA receptor-dependent synchronization leads to ictogenesis in the human dysplastic cortex. Brain 127:1626-1640.

Davenport CJ, Brown WJ, Babb TL (1990) Sprouting of GABAergic and mossy fiber axons in dentate gyrus following intrahippocampal kainate in the rat. Exp Neurol 109:180-190.

De Deyn PP, Marescau B, MacDonald RL (1990) Epilepsy and the GABAhypothesis a brief review and some examples. Acta Neurol Belg 90:65-81.

DeFelipe J, Garcia Sola R, Marco P, del Rio MR, Pulido P, Ramon y Cajal S (1993) Selective changes in the microorganization of the human epileptogenic neocortex revealed by parvalbumin immunoreactivity. Cereb Cortex 3:39-48.

de Lanerolle NC, Kim JH, Robbins RJ, Spencer DD (1989) Hippocampal interneuron loss and plasticity in human temporal lobe epilepsy. Brain Res 495:387-395.

del Rio MR, DeFelipe J (1996) Colocalization of calbindin D-28k, calretinin, and GABA immunoreactivities in neurons of the human temporal cortex. J Comp Neurol 369:472-482.

Di Paolo G, Moskowitz HS, Gipson K, Wenk MR, Voronov S, Obayashi M, Flavell R, Fitzsimonds RM, Ryan TA, De Camilli P (2004) Impaired PtdIns(4,5)P2 synthesis in nerve terminals produces defects in synaptic vesicle trafficking. Nature 431:415-422.

Ferrer I, Tunon T, Soriano E, del Rio A, Iraizoz I, Fonseca M, Guionnet N (1992) Calbindin immunoreactivity in normal human temporal neocortex. Brain Res 572:33-41.

Ferrer I, Oliver B, Russi A, Casas R, Rivera R (1994) Parvalbumin and calbindin-D28k immunocytochemistry in human neocortical epileptic foci. J Neurol Sci 123:18-25.

Garbelli R, Munari C, De Biasi S, Vitellaro-Zuccarello L, Galli C, Bramerio M, Mai R, Battaglia G, Spreafico R (1999) Taylor's cortical dysplasia: a confocal and ultrastructural immunohistochemical study. Brain Pathol 9:445-461.

Gibbs III JW, Zhang YF, Kao CQ, Holloway KL, Oh KS, Coulter DA (1996) Characterization of GABAA receptor function in human temporal cortical neurons. J Neurophysiol 75:1458-1471.

Hannan AJ, Servotte S, Katsnelson A, Sisodiya S, Blakemore C, Squier M, Molnar Z (1999) Characterization of nodular neuronal heterotopia in children. Brain 122:219-238.

Hiscock JJ, Murphy S, Willoughby JO (2000) Confocal microscopic estimation of GABAergic nerve terminals in the central nervous system. J Neurosci Methods 95:1-11.

Houser CR, Harris AB, Vaughn JE (1986) Time course of the reduction of GABA terminals in a model of focal epilepsy: a glutamic acid decarboxylase immunocytochemical study. Brain Res 383:129-145.

Isaacson JS, Solis JM, Nicoll RA (1993) Local and diffuse synaptic actions of GABA in the hippocampus. Neuron 10:165-175.

Isokawa-Akesson M, Wilson CL, Babb TL (1989) Inhibition in synchronously firing human hippocampal neurons. Epilepsy Res 3:236-247.

Jefferys JG, Whittington MA (1996) Rev of the role of inhibitory neurons in chronic epileptic foci induced by intracerebral tetanus toxin. Epilepsy Res 26:59-66.

Kamphuis W, Huisman E, Wadman WJ, Heizmann CW, Lopes da Silva FH (1989) Kindling induced changes in parvalbumin immunoreactivity in rat hippocampus and its relation to long-term decrease in GABAimmunoreactivity. Brain Res 479:23-34.

Kellinghaus C, Kunieda T, Ying Z, Pan A, Lüders HO, Najm IM (2004) Severity of histopathologic abnormalities and in vivo epileptogenicity in the in utero radiation model of rats is dose dependent. Epilepsia 45:583-591.

Kobayashi M, Buckmaster PS (2003) Reduced inhibition of dentate granule cells in a model of temporal lobe epilepsy. J Neurosci 23:2440-2452.

Kobayashi M, Wen X, Buckmaster PS (2003) Reduced inhibition and increased output of layer II neurons in the medial entorhinal cortex in a model of temporal lobe epilepsy. J Neurosci 23:8471-8479.

Loup F, Wieser HG, Yonekawa Y, Aguzzi A, Fritschy JM (2000) Selective 
alterations in $\mathrm{GABA}_{\mathrm{A}}$ receptor subtypes in human temporal lobe epilepsy. J Neurosci 20:5401-5419.

Macdonald RL, Kapur J (1999) Acute cellular alterations in the hippocampus after status epilepticus. Epilepsia 40 [Suppl 1]:S9-S20; discussion S21-S22.

Marco P, Sola RG, Pulido P, Alijarde MT, Sanchez A, Ramon y Cajal S, DeFelipe J (1996) Inhibitory neurons in the human epileptogenic temporal neocortex. An immunocytochemical study. Brain 119:1327-1347.

Mathern GW, Babb TL, Pretorius JK, Leite JP (1995) Reactive synaptogenesis and neuron densities for neuropeptide $\mathrm{Y}$, somatostatin, and glutamate decarboxylase immunoreactivity in the epileptogenic human fascia dentata. J Neurosci 15:3990-4004.

McCormick DA (1989) GABA as an inhibitory neurotransmitter in human cerebral cortex. J Neurophysiol 62:1018-1027.

Miller JW, Ferrendelli JA (1990) Characterization of GABAergic seizure regulation in the midline thalamus. Neuropharmacology 29:649-655.

Mischel PS, Nguyen LP, Vinters HV (1995) Cerebral cortical dysplasia associated with pediatric epilepsy. Rev of neuropathologic features and proposal for a grading system. J Neuropathol Exp Neurol 54:137-153.

Najm IM, Ying Z, Babb T, Mohamed A, Hadam J, LaPresto E, Wyllie E, Kotagal P, Bingaman W, Foldvary N, Morris H, Luders HO (2000) Epileptogenicity correlated with increased $N$-methyl-D-aspartate receptor subunit NR2A/B in human focal cortical dysplasia. Epilepsia 41:971-976.

Otis TS, Mody I (1992) Modulation of decay kinetics and frequency of GABAA receptor-mediated spontaneous inhibitory postsynaptic currents in hippocampal neurons. Neuroscience 49:13-32.

Otis TS, Trussell LO (1996) Inhibition of transmitter release shortens the duration of the excitatory synaptic current at a calyceal synapse. J Neurophysiol 76:3584-3588.

Palmini A, Najm I, Avanzini G, Babb T, Guerrini R, Foldvary-Schaefer N, Jackson G, Luders HO, Prayson R, Spreafico R, Vinters HV (2004) Terminology and classification of the cortical dysplasias. Neurology 62:S2-S8.

Patrylo PR, Spencer DD, Williamson A (2001) GABA uptake and heterotransport are impaired in the dentate gyrus of epileptic rats and humans with temporal lobe sclerosis. J Neurophysiol 85:1533-1542.

Porter BE, Judkins AR, Clancy RR, Duhaime A, Dlugos DJ, Golden JA (2003) Dysplasia: a common finding in intractable pediatric temporal lobe epilepsy. Neurology 61:365-368.

Powell EM, Campbell DB, Stanwood GD, Davis C, Noebels JL, Levitt P (2003) Genetic disruption of cortical interneuron development causes region- and GABA cell type-specific deficits, epilepsy, and behavioral dysfunction. J Neurosci 23:622-631.

Ribak CE, Hunt CA, Bakay RA, Oertel WH (1986) A decrease in the number of GABAergic somata is associated with the preferential loss of GABAergic terminals at epileptic foci. Brain Res 363:78-90.

Roper SN, Eisenschenk S, King MA (1999) Reduced density of parvalbumin- and calbindin D28-immunoreactive neurons in experimental cortical dysplasia. Epilepsy Res 37:63-71.

Rosen GD, Jacobs KM, Prince DA (1998) Effects of neonatal freeze lesions on expression of parvalbumin in rat neocortex. Cereb Cortex 8:753-761.

Soudijn W, van Wijngaarden I (2000) The GABA transporter and its inhibitors. Curr Med Chem 7:1063-1079.

Spreafico R, Battaglia G, Arcelli P, Andermann F, Dubeau F, Palmini A, Olivier A, Villemure JG, Tampieri D, Avanzini G, Avoli M (1998a) Cortical dysplasia: an immunocytochemical study of three patients. Neurology 50:27-36.

Spreafico R, Pasquier B, Minotti L, Garbelli R, Kahane P, Grand S, Benabid AL, Tassi L, Avanzini G, Battaglia G, Munari C (1998b) Immunocytochemical investigation on dysplastic human tissue from epileptic patients. Epilepsy Res 32:34-48.

Spreafico R, Tassi L, Colombo N, Bramerio M, Galli C, Garbelli R, Ferrario A, Lo Russo G, Munari C (2000) Inhibitory circuits in human dysplastic tissue. Epilepsia 41 [Suppl 6]:S168-S173.

Stuart GJ, Dodt HU, Sakmann B (1993) Patch-clamp recordings from the soma and dendrites of neurons in brain slices using infrared video microscopy. Pflügers Arch 423:511-518.

Tasker JG, Dudek FE (1991) Electrophysiology of GABA-mediated synaptic transmission and possible roles in epilepsy. Neurochem Res 16:251-262.

Telfeian AE, Connors BW (1998) Layer-specific pathways for the horizontal propagation of epileptiform discharges in neocortex. Epilepsia 39:700-708.

Thom M, Martinian L, Parnavelas JG, Sisodiya SM (2004) Distribution of cortical interneurons in grey matter heterotopia in patients with epilepsy. Epilepsia 45:916-923.

Thompson SM, Gahwiler BH (1992) Effects of the GABA uptake inhibitor tiagabine on inhibitory synaptic potentials in rat hippocampal slice cultures. J Neurophysiol 67:1698-1701.

Van Brederode JF, Mulligan KA, Hendrickson AE (1990) Calcium-binding proteins as markers for subpopulations of GABAergic neurons in monkey striate cortex. J Comp Neurol 298:1-22.

Vreugdenhil M, Jefferys JG, Celio MR, Schwaller B (2003) Parvalbumindeficiency facilitates repetitive IPSCs and gamma oscillations in the hippocampus. J Neurophysiol 89:1414-1422.

Williamson A, Patrylo PR, Spencer DD (1999) Decrease in inhibition in dentate granule cells from patients with medial temporal lobe epilepsy. Ann Neurol 45:92-99.

Wittner L, Eross L, Czirjak S, Halasz P, Freund TF, Magloczky Z (2005) Surviving CA1 pyramidal cells receive intact perisomatic inhibitory input in the human epileptic hippocampus. Brain 128:138-152.

Zappone CA, Sloviter RS (2004) Translamellar disinhibition in the rat hippocampal dentate gyrus after seizure-induced degeneration of vulnerable hilar neurons. J Neurosci 24:853-864.

Zhu WJ, Roper SN (2000) Reduced inhibition in an animal model of cortical dysplasia. J Neurosci 20:8925-8931. 